\section{VITAMIN K PROPHYLAXIS - EVIDENCE VERSUS PREFERENCE. A NATIONAL SURVEY}

\author{
R.A. Khan, E. Gordon
}

Paediatrics and Neonatology, Our Lady of Lourdes Hospital, Drogheda, Ireland

Introduction: Newborns have precariously low vitamin $\mathrm{K}$ stores making it difficult to monitor the long-term effects of vitamin $\mathrm{K}$ administration. To date there are no national guidelines available in Ireland.

Aim: To evaluate the opinions of Consultant Paediatrians, Neonatologists and Paed. Haematologists regarding preferred dose and route of Vit $\mathrm{K}$ in term \& Pre term infants. We asked them to provide information regarding their experience on Haemorrhagic disease of the newborn(HDN).

Methods: An anonymous questionnaire was posted with return envelope to health care providers regarding their practice of vitamin $\mathrm{K}$ prophylaxis regarding their preferred route and dose of vitamin $K$.The return questionnaire's data was entered into Microsoft Excel sheet and then to Stats Direct.

Results: The over all response rate was $66.6 \% .38 \%$ of healthcare providers have 0-5 years experience in their specialities. $90 \%$ of all healthcare providers recommend prophylactic use. $92 \%$ prefer to give Vit K1 Konakion to term \& pre term newborns. 86\% of Units have guidelines for Vit K.70\% recommend $1.0 \mathrm{mg}$ dose.Majority of healthcare providers opted for intramuscular route.62\% recommend $0.5 \mathrm{mg}$ of vitamin $\mathrm{K} .74 \%$ of all healthcare providers advised intramuscular route in preterm. Majority of healthcare providers have not come across a case of HDN over the last 5 to 10 years.

Conclusion: There is a wide range of opinion and preferences among healthcare providers regarding vit $\mathrm{K}$ prophylaxis but in majority of the cases the dosage schedules are in line with AAP and NICE guidelines. A National Guideline on Vitamin $\mathrm{K}$ dosage has been recommended.
1452

\section{SEROCONVERSION RATES IN CELIAC DISEASE AFTER HBV VACCINATION}

\author{
S. Pontari ${ }^{1}$, G. Bedogni ${ }^{1}$, M. Garotta ${ }^{1}$, \\ L. Prampolini ${ }^{1}$, E. Torresani ${ }^{2}$, A. Boccazzi ${ }^{1}$, \\ C. Agostoni ${ }^{1}$
}

${ }^{1}$ Pediatrics, Department of Maternal and Pediatric Sciences, Fondazione IRCCS Cà Granda Ospedale Maggiore Policlinico, Univesity of Milan, ${ }^{2}$ Pediatrics, UO Laboratorio Analisi Chimico Cliniche e Microbiologia, Fondazione IRCCS Cà Granda - Ospedale Maggiore Policlinico, Univesity of Milan, Milan, Italy

Celiac disease (CD) is a condition potentially impairing seroconversion against hepatitis $B$ virus (HBV). Methods. We studied retrospectively 81 consecutive $\mathrm{CD}$ patients (24 $\mathrm{M}$ and $57 \mathrm{~F}$ ) with a median (interquartile range, IQR) age of 10 (7) yr (range 2-30 yr) and 50 controls (26 M and 24 F) with a median (IQR) age 7 (7) yr (range 1-26 yr) who received a standard anti-HBV vaccination schedule at 3,5 and 11 months of age. Subjects affected by autoimmune and neoplastic diseases or immunosuppressive treatment where excluded from the study.

Results: The median (IQR) interval from the last dose of vaccine was higher in CD patients as compared to controls [10 (7), range 2-29 yr vs. 6 (7), range 1-26 yr, p < 0.0001]. The median (IQR) age of gluten introduction was comparable in the two groups [6 (1), range 4-12 mo vs. 6 (1), range 5-11 mo]. The median (IQR) duration of gluten intake in the CD group was 3.5 (4.8) yr (range 0.2$12.3 \mathrm{yr}$ ). A cut-point $\geq 10 \mathrm{mUl} / \mathrm{ml}$ for HbsAg title was considered to indicate seroconversion for HBV vaccination. 33/81 CD patients did not seroconverte compared to $10 / 50$ controls $(p<0.05)$. The Odds ratio of a protective $\mathrm{HbsAg}$ title in $\mathrm{CD}$ subjects vs. controls was $0.36(95 \% \mathrm{Cl}, 0.16-0.83, \mathrm{p}<0.0001)$ and was not associated with gender, the interval from the last administration of the vaccine nor with the duration of gluten intake in CD patients. 